\title{
Experimental Investigation of Slurry Erosion Behaviour of Hard Faced AISI 316L Stainless Steel
}

\author{
Gulovleen Singh, Roshan Lal Virdi, Khushdeep Goyal* \\ Department of Mechanical Engineering, Punjabi University, India
}

Copyright (C) 2015 Horizon Research Publishing All rights reserved.

\begin{abstract}
The slurry Erosion behaviour of AISI 316L stainless steel has been investigated in this research work. The samples hard faced with cobalt based (stellite-6) and titanium based alloys specimens were used during the experimentation. Erosion test was performed on a Slurry Erosion test rig fabricated as per ASTM standards G73. Three variables which were used in the experimentation are concentration level of the Slurry, nozzle diameter of the jet and average particle size of erodent. After a fix time, weight loss of samples was compared. It was found that the samples hard faced with titanium based alloy are more hard than hard faced with cobalt based alloy and substrate material.
\end{abstract}

Keywords Slurry Erosion, Hard Facing, Coating, Impact, Particle Size

\section{Introduction}

Erosion is the degradation of the solid target surface due to impingement of solid and/or liquid particles. In slurry erosion, material is removed from the target surface due to impingement of solid particles entrained in liquid medium [1]. Slurry erosion of turbine components is a very serious problem in hydraulic power plants in Himalayan region of India. During the monsoon season, a sudden increase in the concentration of solid particles impacting the turbine components even leads to shut down of the hydro power plants[2]. Slurry erosion also affects the fluid machineries in mining, agricultural sector and petroleum industry [3]. In many industrial applications, the components that are in contact with liquid also contains hard particles that accelerates the material loss [4]. Erosion leads to changes in surface dimensions, and contribute to the fatigue failure of components. Many researchers have studied the slurry erosion behavior of hydro power plant components under various operating parameters. Grewal et al. [1] proposed a parameter to predict the mechanism of erosion as erosion mechanism identifier. It was observed that this parameter is able to predict the erosion mechanism for ductile and brittle materials. The prediction of this parameter was not constrained by different operating conditions. Goyal et al. [2] investigated the slurry erosion behavior of $\mathrm{WC}-10 \mathrm{Co}-4 \mathrm{Cr}$ and $\mathrm{Al}_{2} \mathrm{O}_{3}+13 \mathrm{TiO}_{2}$ coatings deposited on CF8M turbine steel. The coatings were deposited by High Velocity Oxy Fuel (HVOF) process. Three parameters namely average particle size, speed(rpm), and slurry erosion were studied. It was concluded that erosion of bare and $\mathrm{Al}_{2} \mathrm{O}_{3}+13 \mathrm{TiO}_{2}$ coatings was due to ductile and brittle fracture. . On the other hand, WC-10Co-4Cr showed mixed behavior (mainly ductile). Dallaire et al. [3] studied the slurry erosion resistance of boride based overlays containing boride crystals. Gas metal arc welding (GMAW) process was used for overlaying process. Fe-Mo-B-C-Si GMAW overlays were deposited with defined welding parameters. It was found that the boride crystals oriented perpendicularly to the wearing surface contributed significantly to improve the erosion resistance. Due to carbon and molybdenum resistance is higher especially at 90 , it toughen the steel supporting matrix containing very fine $\mathrm{Fe}_{2} \mathrm{~B}$ crystals. Neville et al. [4] studied the erosion-corrosion behavior of WC-Metal Matrix Composites (EFM, EFW, EGC, EGG). The materials were eroded by two sizes of silica sand with stream velocities of 10 and $17 \mathrm{~m} / \mathrm{s}$ at $65 \circ \mathrm{C}$. Test was conducted by varying the concentration. They evaluated that $\mathrm{WC}$ grain size fractions has very little effect on wear. They also concluded that the erosion-corrosion rate is strongly dependent upon erodent size, impinging velocity and solid loading. Flores et al. [5] had investigated the microstructure and erosion-corrosion behavior of a $\mathrm{Fe}-\mathrm{Cr}-\mathrm{C}$ overlay produced by plasma transferred arc welding. Two different temperatures (20 and $65^{\circ} \mathrm{C}$ ) and sand concentrations ( 10 and $\left.50 \mathrm{~g} / \mathrm{l}\right)$ were used in a solution of $1000 \mathrm{ppm}$ of $\mathrm{Cl}$. It was found that at $20^{\circ} \mathrm{C}$, the erosion was due to micro-cutting and micro-ploughing degradation processes. it was followed by plastic flow. At $65^{\circ} \mathrm{C}$, the mechanism of higher degradation due to the selective dissolution of dendritic structure was observed. Chauhan et al. [6] have done the comparative study of a martensitic stainless steel and nitronic steels. It is observed that the 21-4-N nitronic steel showed better resistance to erosion in comparison to $13 / 4$ martensitic stainless steel. The higher erosion resistance of nitronic steel was due to high hardness, high tensile toughness and work hardening ability. Singh et al. [7] investigated the erosive wear behaviour of hydraulic turbine material. The samples of CA6NM steel 
were coated by $(50 \%)$ WC-Co-Cr and $(50 \%)$ Ni-Cr-B-Si powder with plasma thermal spray technique. It was observed that the coated samples have better erosion resistance than uncoated samples.

It is clear from the literature review that there is no systematic study done on any hard faced alloy. It is important to investigate the slurry Erosion behaviour of AISI 316L stainless steel. These investigations could help to improve the performance of this steel in real working environments.

\section{Experimentation}

\section{Material}

The subject material for the research i.e. AISI 316L stainless steel was purchased from Bombay Steels Pvt. Ltd. Ludhiana. This material is usually regarded as the standard "marine grade stainless steel". This material is used to manufacture the impellers of centrifugal pumps used in agricultural sector. The austenitic structure also gives these grades excellent toughness. Spectroscopy analysis performed at Munjal Castings Pvt. Ltd. Ludhiana to ensure the chemical composition of the material.

\section{Surface improvement by hard facing technique}

The base material i.e. AISI 316L stainless steel was Hard Faced with Cobalt based (stellite 6) and Titanium based electrodes. The welding was accomplished with SMAW process. The nominal composition of cobalt based and titanium based electrodes are given in the next chapter. The parameters taken during the welding process are presented in the table 1.

Table 1. Welding parameters during hard facing process

\begin{tabular}{|c|c|}
\hline Welding Process & SMAW \\
\hline Preheat temperature $(\mathrm{C})$ & 150 \\
\hline Inter-pass temperature $(\mathrm{C})$ & $150-200$ \\
\hline Welding current $(\mathrm{A})$ & $90-120$ \\
\hline
\end{tabular}

\section{Erosion Test Rig}

Figure 1 shows the erosion test rig used in this experimentation.

\section{Results and Discussion}

\section{Comparison of Cumulative Erosion Behavior of Bare Material Specimen and the Specimens Hard Faced with Hard Alloy 1 and Hard Alloy 2}

The table 2 and plot shown in the figure 2 illustrates the comparison of cumulative mass loss $\left(\mathrm{mg} / \mathrm{cm}^{2}\right)$ at various runs for bare material and hard faced material with hard facing alloy 1 and alloy 2 . The maximum erosion takes place for bare material specimens and minimum erosion is for hard facing alloy 2. This may be due to more hardness of the hard facing alloy 2. As shown in the chart, there is maximum erosion for all the three type of specimens at run 4 and at run 8 and minimum erosion at run 1 and run 2 . The performance of hard facing alloy 2 is best among all of the three type of samples.

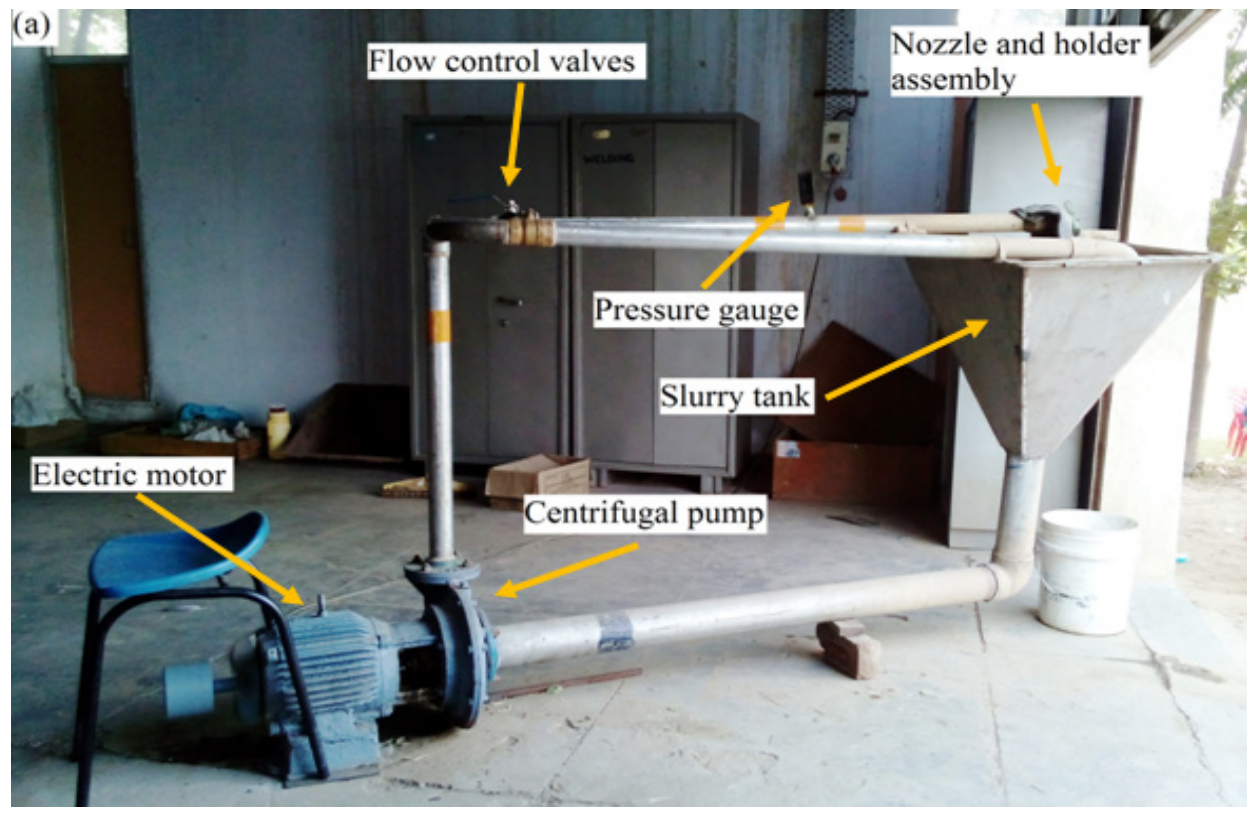

Figure 1. Erosion test rig

Table 2. Cumulative mass loss $\left(\mathrm{mg} / \mathrm{cm}^{2}\right)$ of various specimens for different runs after completion of experiment

\begin{tabular}{|c|c|c|c|c|c|c|c|c|}
\hline Various specimens & run 1 & run 2 & run 3 & run 4 & run 5 & run 6 & run 7 & run 8 \\
\hline Bare & 12.5 & 12.5 & 15.277 & 20.8333 & 13.8888 & 15.2777 & 16.6666 & 18.0555 \\
\hline HF with alloy 1 & 11.1111 & 11.1111 & 12.5 & 20.8333 & 11.1111 & 12.5 & 15.27777 & 18.0555 \\
\hline HF with alloy2 & 11.1111 & 11.1111 & 12.5 & 18.0555 & 11.1111 & 11.1111 & 13.8888 & 16.6666 \\
\hline
\end{tabular}




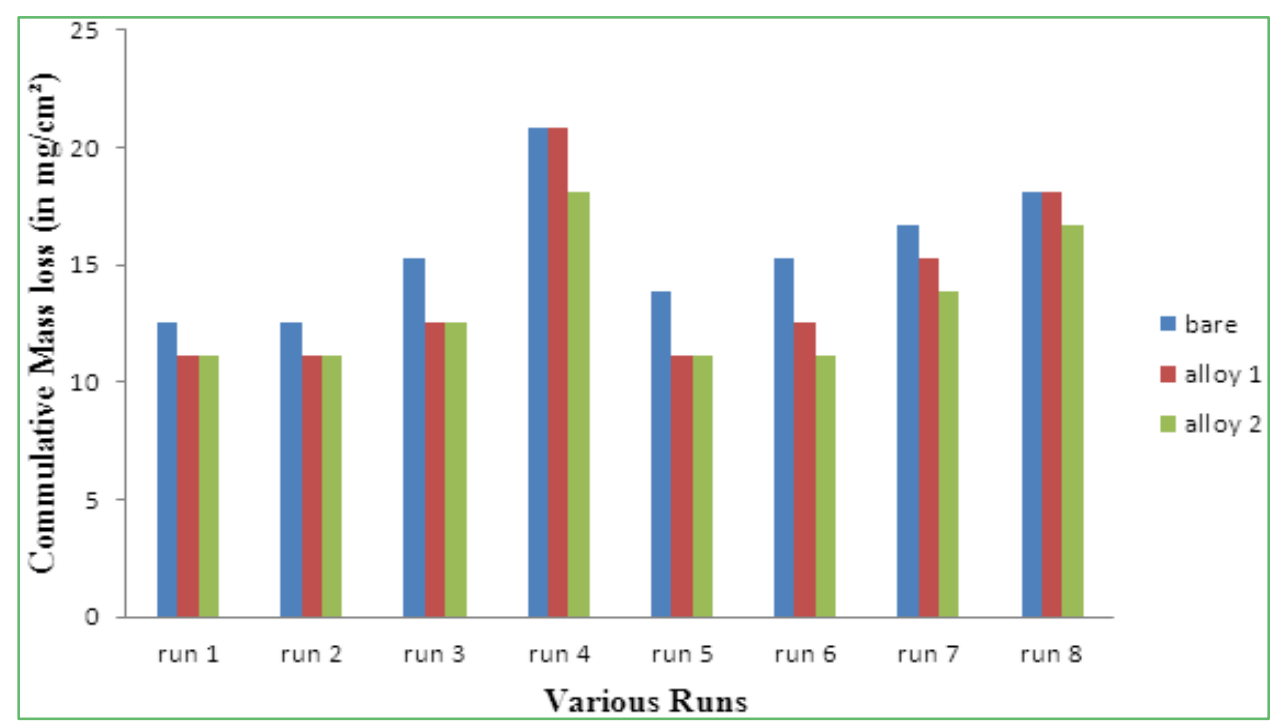

Figure 2. Comparison of cumulative erosion behavior of different specimens at various runs

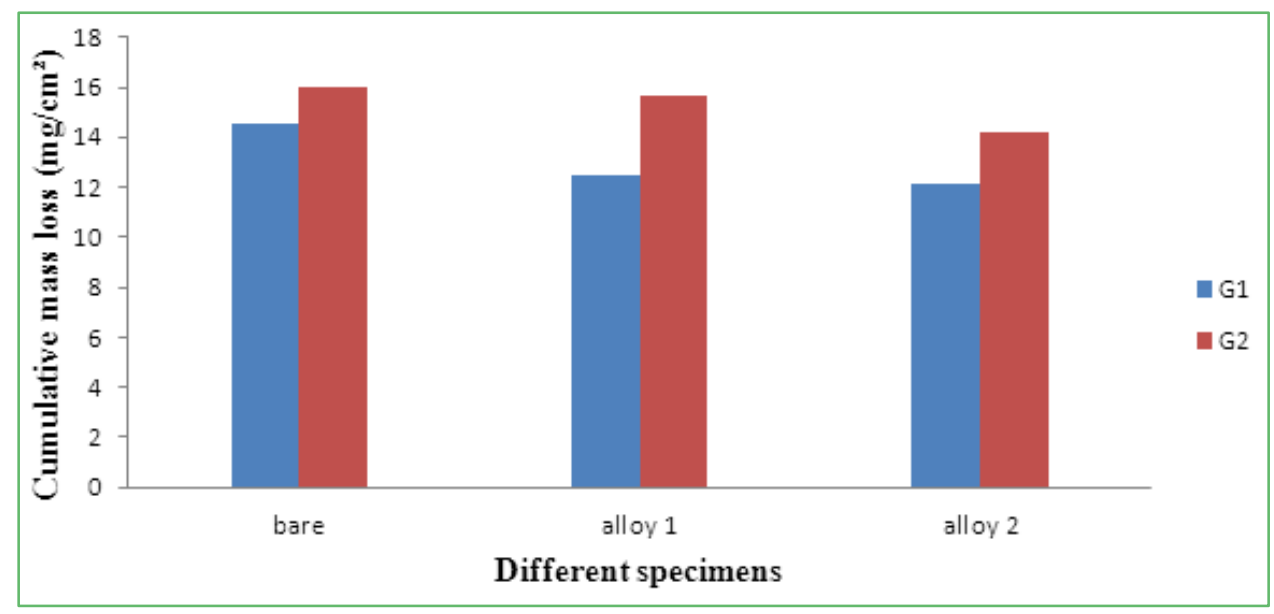

Figure 3. Effect of average particle size on the slurry erosion for different samples

Effect of Different Parameters on the Slurry Erosion Performance of Various Samples of Aisi 3161 Stainless Steel

Effect of Average Particle Size on the Slurry Erosion

To evaluate the effect of average particle size on the slurry erosion, the experiment was conducted at two different levels of particle size $(300 \mu \mathrm{m}$ and $600 \mu \mathrm{m})$. Table 3 shows average particle size. As shown in the figure 3, the effect of average particle size on the slurry erosion was calculated on the basis of cumulative mass loss (in $\mathrm{mg} / \mathrm{cm}^{2}$ ) for all three type of different samples.

Table 3. Effect of average particle size on slurry erosion for different specimens

\begin{tabular}{|c|c|c|}
\hline Various specimens & G1 $(300 \mu \mathrm{m})$ & G2 $(600 \mu \mathrm{m})$ \\
\hline Bare & 14.58218 & 15.9722 \\
\hline HF with alloy 1 & 12.49998 & 15.62498 \\
\hline HF with alloy 2 & 12.15275 & 14.23608 \\
\hline
\end{tabular}

The average particle size plays a significant role in the slurry erosion. As shown in the plot, there is more erosion when bigger particle size was used in the slurry. Rate of erosion increased with increase in particle size. These results were similar to as reported by various authors $[8,9]$.

\section{Effect of Slurry Concentration on Slurry Erosion}

To evaluate the effect of level of concentration on the slurry erosion, the experiment was conducted by using two levels of slurry concentration (40,000 ppm and 60,000 ppm). Table 4 shows level of conenctration. bThe effect of concentration level on slurry erosion was calculated on the basis of mass loss (in $\mathrm{mg} / \mathrm{cm}^{2}$ ) for each level of concentration for different samples.

Table 4. Effect of level of concentration of the slurry on slurry erosion for different specimens

\begin{tabular}{|c|c|c|}
\hline Various specimens & $\mathrm{C} 1(40,000 \mathrm{ppm})$ & $\mathrm{C} 2(60,000 \mathrm{ppm})$ \\
\hline Bare & 13.54163 & 17.70718 \\
\hline HF with alloy 1 & 11.45833 & 16.66663 \\
\hline HF with alloy 2 & 11.1111 & 15.27773 \\
\hline
\end{tabular}




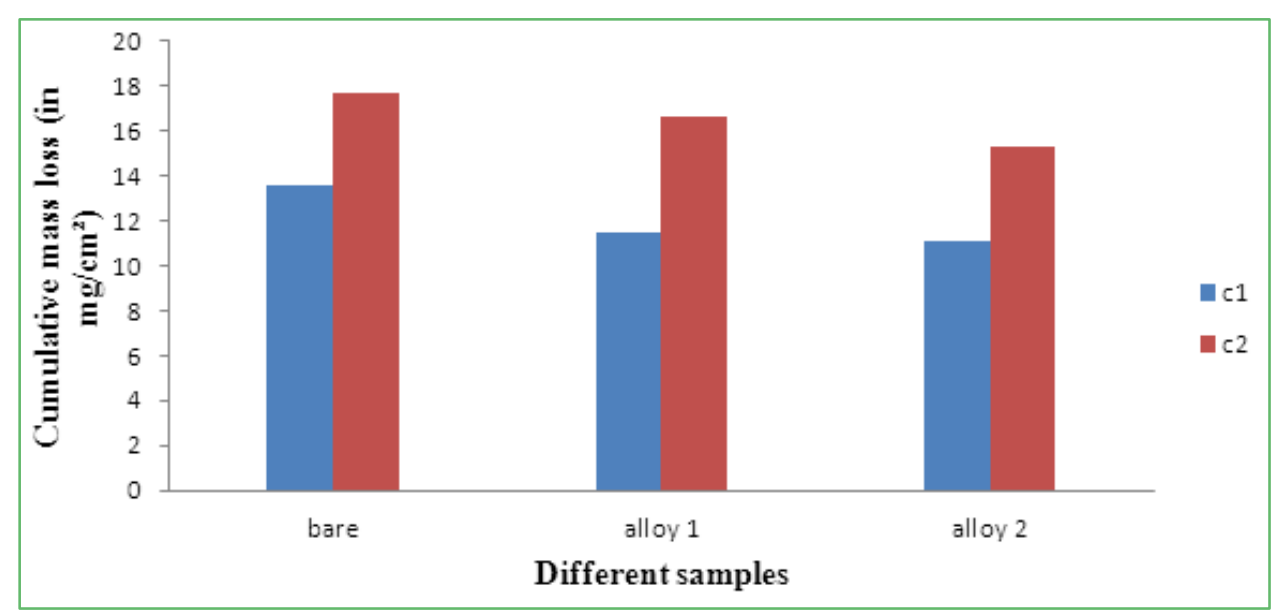

Figure 4. Effect of slurry concentration on slurry erosion for different samples

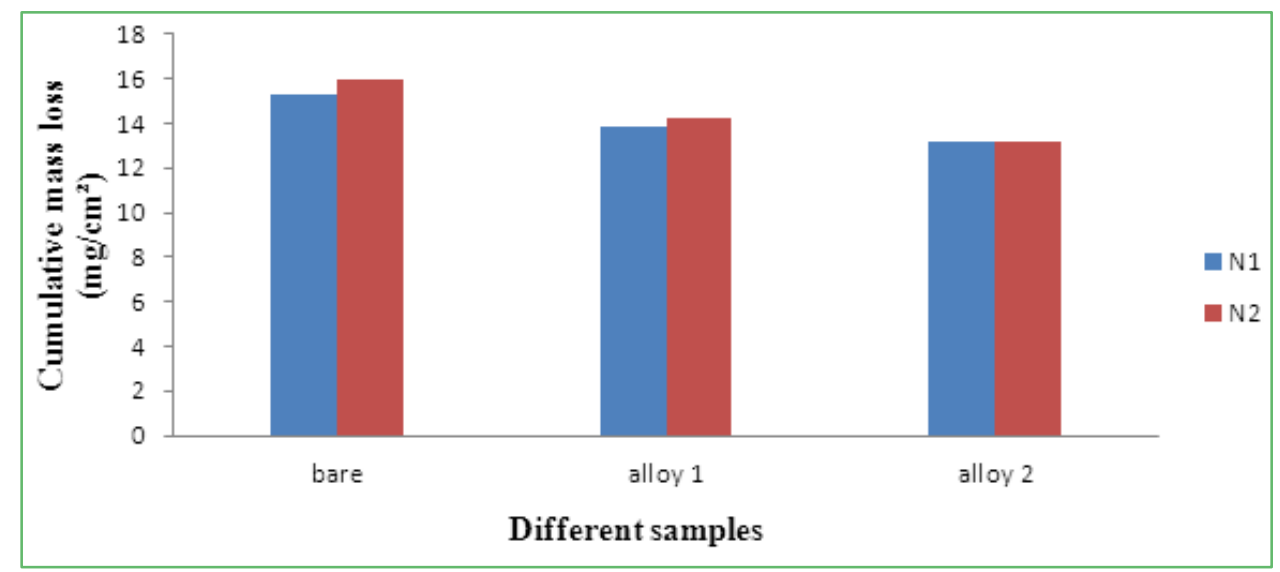

Figure 5. Effect of nozzle diameter of the jet on slurry erosion for various samples

As shown in the figure 4, the level of concentration plays a significant role in the erosion behavior. As the concentration is more, it means more particles are suspended in the water and hence the attack on the surface will be more severe. It is clear from the plot that there is more erosion takes place when higher concentration is used and less erosion when lower concentration is used. The hard faced specimens showed better performance than the bare. These results were similar to as reported by various authors $[2,10,11]$.

\section{Effect of Nozzle Diameter of the jet on Slurry Erosion}

To evaluate the effect of nozzle diameter of the jet on the slurry erosion, the experiment was conducted by using two sizes of the nozzle diameter $(3 \mathrm{~mm}$ and $5 \mathrm{~mm})$. The effect of nozzle diameter on slurry erosion was calculated on the basis of mass loss (in $\mathrm{mg} / \mathrm{cm}^{2}$ ) for each level of nozzle diameter used for different samples. Table 5 shows concentration of slurry.

The plot shown in the figure 5 depicts that there is no any significant role of nozzle diameter of the jet on slurry erosion. The second level of nozzle size show some effect in the case of bare specimen and hardfaced with alloy 1 but no any significant effect in the case of hard faced with alloy 2 . Similar results were reported by various authors $[7,9,10]$.
Table 5. Effect of concentration of the slurry on slurry erosion for different specimens

\begin{tabular}{|c|c|c|}
\hline Various specimens & N1 $(3 \mathrm{~mm})$ & N2 $(5 \mathrm{~mm})$ \\
\hline Bare & 15.27665 & 15.97215 \\
\hline HF with alloy 1 & 13.8888 & 14.23609 \\
\hline HF with alloy 2 & 13.19443 & 13.1944 \\
\hline
\end{tabular}

\section{Conclusions}

The conclusions made from the experimentation results are listed below:

- The comparison of mass loss (in $\mathrm{mg} / \mathrm{cm}^{2}$ ) shows that erosion rate of AISI 316L stainless steel is more than that of hard faced steel samples.

- The hard faced samples show better performance than the bare steel in all experimental conditions.

- The maximum erosion takes place at average particle size of $600 \mu \mathrm{m}$, level of concentration is $60,000 \mathrm{ppm}$, size of nozzle diameter $3 \mathrm{~mm}$, angle of impingement is 90 and velocity of $40 \mathrm{~m} / \mathrm{s}$.

- The samples hard faced with titanium based alloy are more hard than hard faced with cobalt based alloy and substrate material. 
- The minimum erosion takes place average particle size of $300 \mu \mathrm{m}$, level of concentration is $40,000 \mathrm{ppm}$, size of nozzle diameter $3 \mathrm{~mm}$, impact angle of 90 and velocity of $40 \mathrm{~m} / \mathrm{s}$.

- The erosion of the bare steel under normal impact is due to wear mechanism and micro cutting, but for hard faced samples under similar condition is due to crack formation and deep creaters.

- The sand particles are irregular in shape with sharp edges which are responsible for erosion.

- The size of nozzle diameter has no significant effect upon the erosion rate.

- In all the cases, increasing concentration will increases the erosion rate in uniform manner.

- For hard facings applied on the base materials the erosion is mainly effected by level of concentration, velocity and in the last due to average particle size.

\section{REFERENCES}

[1] H. Grewal, A. Agrawal, and H. Singh, "Identifying Erosion Mechanism: A Novel Approach,” Tribology Letters, vol. 51, no. 1, pp. 1-7, 2013.

[2] D. Kumar Goyal, H. Singh, H. Kumar et al., "Slurry erosion behaviour of $\mathrm{HVOF}$ sprayed $\mathrm{WC}-10 \mathrm{Co}-4 \mathrm{Cr}$ and $\mathrm{Al}<\mathrm{sub}>$ $2</$ sub $>\mathrm{O}<$ sub $>3</$ sub $>+13 \mathrm{TiO}<$ sub $>2</$ sub $>$ coatings on a turbine steel," Wear, vol. 289, pp. 46-57, 2012.

[3] S. Dallaire, "Slurry erosion resistance of boride-based overlays containing boride crystals oriented perpendicularly to the wearing surface," Wear, vol. 297, no. 1, pp. 1006-1015, 2013.

[4] A. Neville, F. Reza, S. Chiovelli et al., "Erosion-corrosion behaviour of WC-based MMCs in liquid-solid slurries," Wear, vol. 259, no. 1, pp. 181-195, 2005.

[5] J. Flores, A. Neville, N. Kapur et al., "Erosion-corrosion degradation mechanisms of $\mathrm{Fe}-\mathrm{Cr}-\mathrm{C}$ and $\mathrm{WC}-\mathrm{Fe}-\mathrm{Cr}-\mathrm{C}$ PTA overlays in concentrated slurries," Wear, vol. 267, no. 11, pp. 1811-1820, 2009.

[6] A. K. Chauhan, D. Goel, and S. Prakash, "Erosion behaviour of hydro turbine steels," Bulletin of Materials Science, vol. 31, no. 2, pp. 115-120, 2008.

[7] H. Singh, K. Goyal, and D. K. Goyal, "Slurry Erosion Behaviour of Plasma Thermal Sprayed (50\%) WC-Co-Cr and Ni-Cr-B-Si Coatings of Different Thickness on CA6NM Turbine Steel Material," Manufacturing Science and Technology, vol. 2, no. 4, pp. 81-92, 2014.

[8] S. Matthews, B. James, and M. Hyland, "Microstructural influence on erosion behaviour of thermal spray coatings," Materials characterization, vol. 58, no. 1, pp. 59-64, 2007.

[9] V. Souza, and A. Neville, "Corrosion and synergy in a WCCoCr HVOF thermal spray coating - understanding their role in erosion-corrosion degradation," Wear, vol. 259, no. 1, pp. 171-180, 2005.

[10] H. Hawthorne, B. Arsenault, J. Immarigeon et al., "Comparison of slurry and dry erosion behaviour of some HVOF thermal sprayed coatings," Wear, vol. 225, pp. 825-834, 1999.

[11] A. Singh, R. L. Virdi, and K. Goyal, "To Study the Slurry Erosion Behaviour of Hard Faced Alloy SS304," Manufacturing Science and Technology, vol. 2, no. 6, pp. 111-115, 2014. 